
por planta. Horticultura Brasileira 26: 209-215.

\title{
Produtividade e qualidade de frutos de meloeiro variando número de frutos e de folhas por planta
}

\author{
Roberto Cleiton F de Queiroga; Mário Puiatti; Paulo Cezar R Fontes; Paulo Roberto Cecon \\ UFV-Deptos. Fitotecnia e Informática, 36570-000 Viçosa-MG; robertocleiton@ hotmail.com
}

\begin{abstract}
RESUMO
O cultivo do meloeiro tipo Cantaloupe no sudeste do Brasil só é possível em ambiente protegido, tornando-se necessário o manejo da planta via poda. Todavia, nessa espécie, crescimento da planta e produção de frutos são limitados pelo tamanho e atividade da fonte e do dreno. O trabalho teve por objetivo avaliar a produtividade e a qualidade de frutos do meloeiro cultivado em ambiente protegido em função de número de frutos e de folhas por planta. Utilizou-se o delineamento experimental de blocos casualizados, em parcelas subdivididas, com 4 repetições. A parcela constou de número de frutos por planta ( 1 ou 2), fixados entre o 6 e $8^{0}$ nós e a subparcela do número de folhas por planta (16; 19; 22 e 25 folhas). A condução da planta com apenas um fruto, quando podada a partir da $22^{\text {a }}$ folha, elevou a área foliar da planta comparada a plantas com dois frutos. Independente do número de folhas, plantas conduzidas com um fruto apresentaram maior massa média de fruto e menor produtividade comercial. A redução de drenos (número de frutos por planta) proporcionou frutos com maior reticulação de casca, espessura da polpa, comprimento, diâmetro, sólidos solúveis totais, açúcares solúveis totais e açúcares não redutores, todavia sem alterar a acidez total titulável (ATT) e a concentração de açúcares redutores. Exceto a ATT, que declinou, e o diâmetro da cavidade de fruto que apresentou resposta quadrática, todas as características avaliadas obtiveram incremento linear com o aumento do número de folhas por planta.
\end{abstract}

Palavras-chave: Cucumis melo, manejo da planta, poda, raleio.

\begin{abstract}
Yield and quality of muskmelon fruits varying fruit and leaf numbers per plant

The muskmelon cultivation in southeast of Brazil is possible in greenhouse but plants should be pruned. However, in this species plant growth and fruit yield are limited by both source and sink size activity. The muskmelon fruit productivity and quality in greenhouse were evaluated as affected by fruit and leaf numbers left in the plant. Split plot scheme, in a randomized blocks design, with four replications were used. The plot consisted of the fruit number per plant $(1$ or 2$)$. The fruits were fixed at betweenthe 6 and $8^{0}$ nodes. The split-plot consisted of the leaf number left in each plant $(16 ; 19$; 22 and 25). When the plant was pruned from the $22^{\text {th }}$ leaf and one fruit/plant was left, the leaf area increased as compared with plants with two fruits. Independently of the number of leaves, plants with only one fruit presented larger mean fruit weight and smaller commercial yield. Sink reduction (fruit number/plant) provided fruits with larger net rind, pulp thickness, length, diameter, total soluble solids, total soluble sugars and no reduced sugars. On the other hand, the number of fruits/plant did not affect the titratable acidity and the reduced sugars. Except for the titratable acidity that declined and the cavity diameter of the fruit that presented quadratic answer, all the characteristics evaluated presented linear increment with the increase in the number of leaves for plant.
\end{abstract}

Keywords: Cucumis melo, plant management, pruning, thinning.

(Recebido para publicação em 24 de abril de 2007; aceito em 14 de abril de 2008)

$\mathrm{O}$ cultivo do meloeiro no sudeste do Brasil só é possível de ser realizado durante o período do verão, em razão da temperatura e radiação elevadas. Todavia, esse período, nessa região, caracteriza-se por apresentar alto índice pluvial o que, além de promover a morte de plantas e dificultar os tratos culturais, contribui para o aparecimento de doenças e pragas que causam redução da área foliar resultando em frutos pequenos, pobremente reticulados, queimados e com baixo teor de açúcares, contribuindo para baixa qualidade dos frutos e produtividade da cultura (Coelho et al., 2003). O uso do ambiente protegido constitui-se em estratégia para contornar esses problemas; todavia, o cultivo do meloeiro em ambiente protegido requer o desenvolvimento de técnicas para sua exploração tais como o manejo das plantas via poda.

As podas visam promover o equilíbrio fonte:dreno via distribuição dos assimilados entre órgãos vegetativo e reprodutivo (Valantin et al., 1998). Em algumas hortaliças, a poda de hastes é utilizada com o objetivo de melhorar o manejo da planta, a produção e a qualidade dos frutos (Andriolo \& Falcão, 2000). Em espécies como pepino, Nomura \& Cardoso (2000) observaram que, apesar da redução da produção e qualidade dos frutos, as plantas suportaram até $25 \%$ de desfolha sem decréscimo significativo na produção. Em meloeiro, a remoção de $50 \%$ das folhas, 21 dias antes da colheita, reduziu a produtividade de 21,6 para 19,8 $\mathrm{t} \mathrm{ha}^{-1}$ e o teor de sólidos solúveis totais de 10,1 para $9,3 \%$, comparado às plantas controle (Long et al., 2004). Esses resulta- dos evidenciam a importância da produção de fotossintetizados pelas folhas, tanto para a produção de frutos quanto para a qualidade desses.

A competição por assimilados entre drenos afeta a taxa de crescimento da planta e a fixação dos frutos em muitas espécies. No tomateiro, o rendimento da cultura é determinado pelo número, tamanho dos frutos e sua qualidade comercial, sendo que a alocação de assimilados da fonte para o dreno depende, principalmente, do número de frutos existentes na planta (Bertin et al., 2001). Assim, o aumento no número de frutos na planta pode aumentar a fração de fotoassimilados alocado nos frutos às expensas do crescimento das partes vegetativas (Andriolo \& Falcão, 2000).

$\mathrm{O}$ aumento de frutos fixados induz à competição por assimilados entre 
drenos e leva a diminuição do peso individual de fruto e do teor de sólidos solúveis totais da polpa em tomate (Bertin et al., 1998) e em melões Cantaloupe (Costa et al., 2004; Valantin et al., 2006). Todavia, em melancia, o aumento de drenos na planta, apesar de reduzir a massa e o teor de sólidos totais dos frutos, elevou a produção por planta (Seabra Júnior et al., 2003).

No meloeiro a razão fonte:dreno pode ser alterada com a poda de hastes e/ou com o desbaste (raleio) de frutos variando, respectivamente, número de folhas por planta e, conseqüentemente, a área foliar (fonte) e a demanda por fotoassimilados (dreno). Portanto, torna-se de fundamental importância o conhecimento sobre a poda do meloeiro visando o seu cultivo, sobretudo, em ambiente protegido de forma a facilitar o manejo da cultura sem, contudo, causar redução da produtividade e qualidade de frutos.

O trabalho teve por objetivo avaliar a produtividade e qualidade de frutos de meloeiro tipo Cantaloupe cultivado em ambiente protegido variando o número de frutos e de folhas na planta.

\section{MATERIAL E MÉTODOS}

$\mathrm{O}$ experimento foi conduzido em casa de vegetação, na área experimental do Departamento de Fitotecnia da Universidade Federal de Viçosa - UFV, de 15/12/05 a 19/03/06. O solo da área, Argissolo Vermelho-Amarelo Câmbico apresentava, na camada de 0-20 cm de profundidade, as características: $5,1(\mathrm{pH}$ em $\left.\mathrm{H}_{2} \mathrm{O}\right) ; 120,1(\mathrm{P})$ e $163,0(\mathrm{~K}) \mathrm{mg} \mathrm{dm}^{-3}$; 5,0 $\left(\mathrm{Ca}^{2+}\right), 1,0\left(\mathrm{Mg}^{2+}\right), 0,0\left(\mathrm{Al}^{3+}\right)$ e 3,3 $(\mathrm{H}+\mathrm{Al}) \mathrm{cmol}_{\mathrm{c}} \mathrm{dm}^{-3}$; 30,9 (Zn), 116,8 (Fe), 161,0 (Mn), 5,7 (Cu) e 1,3 (B) mg $\mathrm{dm}^{-3}$, respectivamente. Durante o período experimental, a temperatura e a umidade relativa do ar no interior da casa de vegetação, registradas por termohigrômetro digital (modelo HT210), colocado à altura do dossel das plantas, apresentou valores médios das máximas e das mínimas de 36,7 e $18,3^{\circ} \mathrm{C}$ e de 95,8 e $34,3 \%$, respectivamente. Utilizou-se casa de vegetação "tipo capela", coberta com filme de polietileno de baixa densidade, aditivado, 0,15 mm de espessura, tendo as frontais e late- rais fechadas até a metade de sua altura.

$\mathrm{O}$ delineamento experimental foi de blocos ao acaso, em parcelas subdivididas, com quatro repetições. A parcela constou do número de frutos por planta (1 ou 2), fixados entre o $6^{0}$ e $8^{0}$ nós, e na subparcela o número de folhas por planta $(16 ; 19 ; 22$ e 25 folhas). Utilizou-se o espaçamento de $1,0 \times 0,3 \mathrm{~m}$; a parcela foi constituída de uma fileira de $16,8 \mathrm{~m}$ de comprimento e a subparcela, com 4,2 $\mathrm{m}$ de comprimento, continha 14 plantas.

Utilizou-se a cultivar Coronado F1, pertencente ao grupo Cantalupensis, que apresenta frutos com pequena cavidade interna, casca rendilhada, polpa cor salmão e alto teor de açúcares (Topseed, 2007). A semeadura foi realizada em 15/ 12/05, em bandejas de poliestireno de 128 células preenchidas com substrato agrícola comercial. O transplante foi realizado em 02/01/06, 18 dias após a semeadura, com a segunda folha completamente expandida.

A correção do solo e a adubação de fundação foram realizadas de acordo com a análise do solo e recomendações para a cultura (Ribeiro et al., 1999). A área experimental recebeu, 60 dias antes do transplante das mudas, calcário dolomítico (2,0 t ha-1) objetivando-se elevar o pH do solo e a saturação por bases a $70 \%$. No sulco de plantio, cinco dias antes do transplante das mudas, aplicou-se (equivalente a $\mathrm{kg} \mathrm{ha}^{-1}$ ): 300 de $\mathrm{P}_{2} \mathrm{O}_{5}$, na forma de superfosfato simples, 200 de sulfato de magnésio, 5 de bórax, 5 de sulfato de zinco e 0,5 de molibdato de amônio. Aplicou-se, também em fundação, o correspondente a $10 \%$ da dose total de $\mathrm{N}$ e de $\mathrm{K}(30 \mathrm{~kg}$ de $\mathrm{N}$ e $15 \mathrm{~kg}$ de $\mathrm{K}_{2} \mathrm{O}$ ), nas formas de uréia e de cloreto de potássio, respectivamente; os $90 \%$ restantes do $\mathrm{N}$ e do $\mathrm{K}$ foram aplicados em cobertura, via fertirrigação. A fertirrigação foi iniciada uma semana após o transplante das mudas aplicando-se, durante o cultivo, $270 \mathrm{~kg} \mathrm{ha}^{-1}$ de $\mathrm{N}$, na forma de uréia, e $135 \mathrm{~kg} \mathrm{ha}^{-1}$ de $\mathrm{K}_{2} \mathrm{O}$, como cloreto de potássio. Em cada fertirrigação, foram aplicados os seguintes $\%$ de $\mathrm{N}$ e de $\mathrm{K}$, respectivamente: $1^{\mathrm{a}}=5$ e $7 \% ; 2^{\mathrm{a}}=8 \mathrm{e}$ $10 \% ; 3^{a}=12$ e $10 \% ; 4^{a}, 5^{a}$ e $6^{a}=20$ e $18 \% ; 7^{a}=10 \%$ e $10 \%$; e $8^{a}=5$ e $9 \%$. Diariamente, fez-se a irrigação por gotejamento, utilizando-se de gotejadores espaçados $0,30 \mathrm{~m}$, com vazão de $2,70 \mathrm{~L} \mathrm{~h}^{-1}$, sendo a necessidade de água a aplicar monitorada com tensiômetros instalados a $10 \mathrm{~cm}$ de profundidade.

As plantas foram conduzidas verticalmente, em haste única, com uso de fitilhos fixados em bambu colocado na horizontal a $1,80 \mathrm{~m}$ do solo e podadas de acordo com o número de folhas desejado. Os frutos, um ou dois por planta, foram fixados nos ramos secundários emitidos entre o $6^{0}$ e $8^{0}$ nós, realizando-se, nesses ramos, a poda duas folhas após o fruto fixado. Todas as demais ramificações foram retiradas. Durante o ciclo da cultura foram realizadas duas capinas manuais e controle fitossanitário com fungicidas e inseticidas sempre que necessário. Foram colocadas duas colméias de abelhas melíferas na parte externa da casa de vegetação para proceder a polinização.

A colheita iniciou-se em 06/03/06, quando os frutos apresentavam a formação da camada de abscisão, ponto indicativo da colheita do fruto. Na colheita dos frutos, avaliaram-se: área foliar da planta $\left(\mathrm{cm}^{2}\right.$ planta $\left.{ }^{-1}\right)$; massa média de fruto $\left(\mathrm{g}_{\text {fruto }}{ }^{-1}\right)$; produtividade comercial $\left(\mathrm{t} \mathrm{ha}^{-1}\right)$; reticulação da casca, atribuindo-se notas de $1(0 \%), 2$ (25\%), $3(50 \%), 4(75 \%)$ e $5(100 \%$ da superfície reticulada); espessura da polpa $(\mathrm{cm})$, avaliada na região equatorial, após seccionar o fruto no sentido longitudinal; diâmetro da cavidade interna $(\mathrm{cm})$, medido no sentido transversal na região equatorial; comprimento $(\mathrm{cm})$ e diâmetro $(\mathrm{cm})$ de fruto, medidos no sentido longitudinal e transversal do fruto; teor de sólidos solúveis totais (SST) e acidez total titulável (ATT), em amostras de fatias de frutos retiradas no sentido longitudinal e homogeneizadas em liquidificador para a obtenção do suco. O SST foi determinado por meio de refratômetro de mesa, modelo ATAGO $3 \mathrm{~T}$, obtendo-se os valores em \%, corrigidos a $20^{\circ} \mathrm{C}$; para ATT, utilizou-se uma alíquota de $10 \mathrm{~mL}$ de suco, em duplicata, à qual foram adicionados $40 \mathrm{~mL}$ de água destilada e três gotas de fenolftaleína alcoólica a $1 \%$ e, em seguida, procedeu-se a titulação com solução de $\mathrm{NaOH} 0,1 \mathrm{~N}$ até o ponto de viragem, com os resultados expressos 
em \% de ácido cítrico. Com a mesma amostra, para a determinação das características anteriores, foi avaliado o açúcar solúvel total (AST), quantificado por meio da reação com Antrona, conforme Yemn \& Willis (1954) e os açúcares redutores (AR), pelo método do DNS (Miller, 1959); os açúcares não-redutores (NR) foram determinados por diferença entre AST e AR.

Consideraram-se comerciais, frutos firmes, uniformes quanto à cor, com bom rendilhamento de casca, sem deformações, murchamento, rachaduras e sinais de podridão, ataque de insetos pragas e de danos mecânicos.

Os dados foram submetidos à análise de variância; as médias entre número de frutos foram comparadas pelo teste de Tukey a $5 \%$ de probabilidade e, entre número de folhas por planta, por regressão. As equações de regressão foram ajustadas com base significância de seus parâmetros pelo teste " $\mathrm{t}$ " ao nível de 1 e $5 \%$ de probabilidade, no valor do $\mathrm{R}^{2} / \mathrm{r}^{2}$, e na resposta biológica.

\section{RESULTADOS E DISCUSSÃO}

Foi observado efeito significativo da interação número de fruto por planta $\mathrm{x}$ número de folhas por planta apenas para a área foliar da planta (AF), massa média de fruto (MMF) e produtividade comercial de frutos (PCF) (Tabela 1).

Plantas conduzidas com dois frutos, quando podadas com 16 folhas, e plantas conduzidas com um fruto, quando podadas com 22 ou 25 folhas, apresentaram maior AF (Tabela 1). Com aumento do número de folhas por planta observou-se incremento linear na AF, tanto em plantas com um quanto com dois frutos; em plantas com um fruto os incrementos estimados foram de 26,3; 52,7 e $79,0 \%$ e, em plantas com dois frutos, de 5,$8 ; 11,6$ e 17,3\%, com o aumento do número de folhas de 16 para 19, 22 e 25, respectivamente (Figura 1).

A maior AF observada em plantas com dois frutos, quando podada com 16 folhas, evidencia que essas plantas apresentaram maior expansão de suas folhas na tentativa de adequar a AF a maior demanda do dreno por assimilados em razão do maior número de frutos (drenos) compensando, assim, a menor

Tabela 1. Valores médios da área foliar, massa fresca de fruto e produtividade comercial do meloeiro cultivado em ambiente protegido em função de número de frutos e de folhas por planta (average values of leaf area, fresh mass of fruit, and commercial yield of melon cultivated in greenhouse in relation to fruit number and leaves per plant). Viçosa, UFV, 2006.

\begin{tabular}{|c|c|c|}
\hline \multirow{2}{*}{$\begin{array}{l}\text { Número de folhas por } \\
\text { planta }\end{array}$} & \multicolumn{2}{|c|}{ Número de frutos por planta } \\
\hline & 1 & 2 \\
\hline & \multicolumn{2}{|c|}{ Área foliar (cm2 planta-1 $\left.^{-1}\right)$} \\
\hline 16 & $4309,1^{*} \mathrm{~b}$ & 5495,8 a \\
\hline 19 & 5848,8 a & 6032,6 a \\
\hline 22 & 6662,8 a & $6206,9 \mathrm{~b}$ \\
\hline 25 & 7932,8 a & $6511,7 \mathrm{~b}$ \\
\hline \multirow[t]{2}{*}{ CV $(\%)$} & 2,141 & 4,382 \\
\hline & \multicolumn{2}{|c|}{ Massa fresca de fruto $\left(\mathrm{g}\right.$ fruto $\left.{ }^{-1}\right)$} \\
\hline 16 & $1146,3^{*} a$ & $814,8 \mathrm{~b}$ \\
\hline 19 & 1261,8 a & $819,5 \mathrm{~b}$ \\
\hline 22 & 1323,0 a & $826,3 \mathrm{~b}$ \\
\hline 25 & 1389,3 a & $857,5 \mathrm{~b}$ \\
\hline \multirow[t]{2}{*}{ CV (\%) } & 5,091 & 2,552 \\
\hline & \multicolumn{2}{|c|}{ Produtividade comercial $\left(\mathrm{t} \mathrm{ha}^{-1}\right)$} \\
\hline 16 & $36,30 \mathrm{~b}$ & $48,89 a$ \\
\hline 19 & $40,38 \mathrm{~b}$ & 49,72 a \\
\hline 22 & $42,78 \mathrm{~b}$ & 50,68 a \\
\hline 25 & $45,38 \mathrm{~b}$ & $53,16 \mathrm{a}$ \\
\hline CV (\%) & 5,201 & 2,402 \\
\hline
\end{tabular}

*Nas linhas, as médias seguidas pela mesma letra não diferem entre sí pelo teste Tukey ao nível de $5 \%$ de probabilidade. ${ }^{1} \mathrm{e}^{2}$ Coeficientes de variação da parcela e subparcela (In lines, means followed by same letter do not differ each other by Tukey test to $5 \% .{ }^{1}$ and $^{2}$ plot splitplot variation coefficients).

relação numérica fonte:dreno (número de folhas:número de frutos). Por outro lado, em plantas com 22 e 25 folhas com apenas um fruto, em razão da maior relação numérica fonte:dreno, a planta reinvestiu as reservas de fotoassimilados disponíveis em seu crescimento vegetativo, conforme observado na cultura do pepino por Nomura \& Cardoso (2000). Valantin et al. (1998) também observaram, na cultura do meloeiro, menor AF com o aumento do número de drenos na planta, fato atribuído à força exercida pelo dreno alterando a expansão e acelerando a senescência das folhas.

Independente do número de folhas por planta, maior MMF foi obtida em plantas conduzidas com apenas um fruto, enquanto que maior PCF foi obtida em plantas com dois frutos (Tabela 1). Com aumento do número de folhas por planta, observaram-se incrementos lineares na MMF e PCF em plantas com um e dois frutos (Figura 1). Em plantas com um fruto, os ganhos estimados, ao incrementar o número de folhas por planta de 16 para 19, 22 e 25 folhas, foram de 6,8; 13,6 e 20,4\% na MMF e de 8,$1 ; 16,1$ e $24,2 \%$ na PCF, e em plantas com dois frutos, foi de 1,7,3,3 e 5,0\% na MMF e de 2,8, 5,7 e 8,5\% na PCF.

$\mathrm{O}$ aumento do número de folhas por planta elevou a MMF, tendo efeito mais pronunciado em plantas conduzidas com um fruto devido à maior $\mathrm{AF}$ disponível por fruto, menor competição entre órgãos vegetativos e reprodutivos e ausência de competição entre frutos na própria planta permitindo, assim, maior alocação de fotoassimilados para crescimento do fruto. Em pepino, Ramirez et al. (1988), observaram que o aumento do nível de desfolha em até $75 \%$ causou redução significativa na MMF, sugerindo que o crescimento dos frutos em cucurbitáceas é limitado pela quantidade de AF na planta.

Segundo Fagan et al. (2006) no meloeiro, quando se aumenta o número de frutos por planta, a demanda dos frutos por fotoassimilados se eleva instalandose forte competição entre frutos, afetando o crescimento destes. Assim, maior número de frutos na planta reduz a MMF 

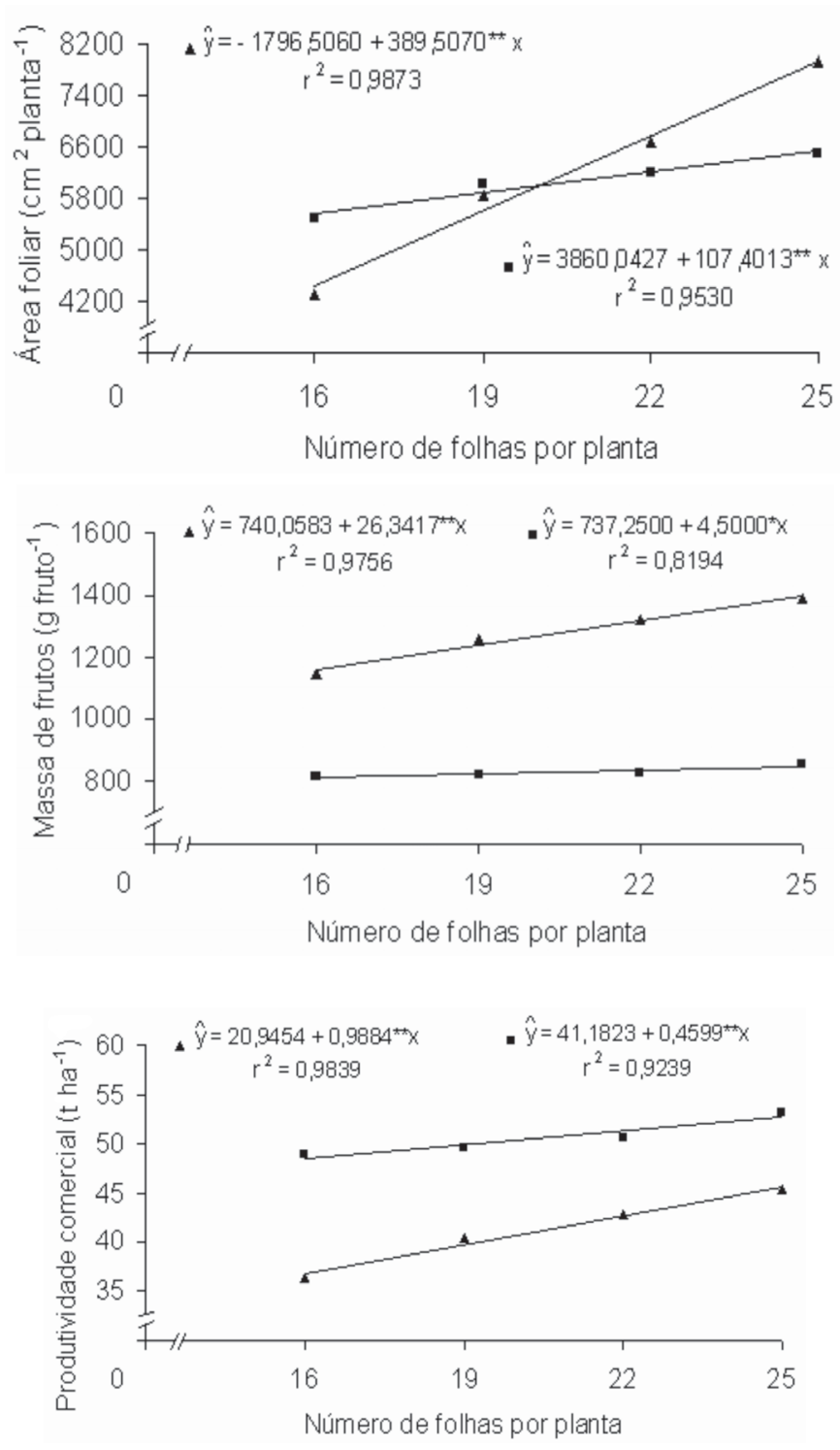

Figura 1. Estimativa da área foliar, massa do fruto e produtividade comercial em plantas conduzidas com um ( $\mathbf{\Delta}$ ) e dois ( $\boldsymbol{(}$ ) frutos de meloeiro cultivado em ambiente protegido em função do número de folhas por planta. ** e * Significativo a 1 e $5 \%$ de probabilidade (estimate of leaf area, mass of fruit and commercial yield in plants leaded with one $(\boldsymbol{\Lambda})$ and two $(\square)$ melon fruits cultivated in greenhouse in relation to leaves number per plant. $* *$ and * significant at 1 and $5 \%$ of probability). Viçosa, UFV, 2006.

demonstrando que a planta tem capacidade produtiva limitada pela fonte. Estes resultados corroboram com àqueles encontrados por Bertin et al. (1998) no tomateiro, Seabra Júnior et al. (2003) em melancia e Valantin et al. (2006) no meloeiro, os quais constataram que a competição por assimilados afeta o tamanho final do fruto.

Plantas conduzidas com dois frutos apresentaram maior PCF em razão da maior demanda do dreno por fotoassimilados. Em melancia, Seabra
Júnior et al. (2003) e, no meloeiro, Fagan et al. (2006) também observaram maior produção em plantas com dois frutos do que com apenas um. Long et al., (2004) também observaram que a prática do raleio de frutos no meloeiro, conduzindo a planta com apenas um fruto, mesmo incrementando a MMF, reduziu a PCF de $31 \mathrm{t} \mathrm{ha}^{-1}$ para $20 \mathrm{t} \mathrm{ha}^{-1}$.

$\mathrm{O}$ incremento na PCF com aumento do número de folhas foi maior em plantas com um fruto, em razão do incre- mento da AF resultar em mais fotoassimilados disponíveis para o fruto. Em pepino, Nomura \& Cardoso (2000) observaram que a desfolha da planta em até $75 \%$ reduziu a produtividade total e comercial; entretanto, não observaram redução significativa na produção com $25 \%$ de desfolha possivelmente em razão das folhas remanescentes terem aumentado a taxa fotossintética como forma de compensar a redução da área foliar.

Houve efeito significativo do número de frutos por planta para reticulação da casca (RC), espessura da polpa ou mesocarpo (EP), comprimento (CF) e diâmetro do fruto (DF), diâmetro da cavidade do fruto (DCF), teores de sólidos solúveis totais (SST), açúcares solúveis totais (AST) e açúcares não redutores (ANR), em que frutos obtidos de plantas com apenas um fruto apresentaram maiores valores para estas características; contudo não houve efeito do número de frutos na planta para a ATT e AR (Tabela 2). Com exceção da ATT, que declinou de forma linear de 0,084 para $0,080 \%$ ao passar de 16 para 25 folhas por planta, e do DCF que apresentou resposta quadrática com máximo estimado de $5,4 \mathrm{~cm}$ com 20,8 folhas por planta, o aumento do número de folhas por planta proporcionou incrementos lineares para as demais características de fruto (Figura 2). Assim, o aumento de 16 para 25 folhas por planta promoveu incrementos estimados de: 0,7 para RC; $0,2 \mathrm{~cm}$ para EP; $0,5 \mathrm{~cm}$ para CF; 0,6 cm para DF; 0,97\% para SST; $0,93 \%$ para AST; $0,1 \%$ para AR e de $0,9 \%$ para ANR (Figura 2).

Aumento do número de folhas, assim como diminuição do número de frutos por planta proporcionou aumento da relação fonte-dreno resultando em mais fotoassimilados disponíveis para crescimento dos frutos, manifestado em termos de EP, CF e DF, e melhores condições para formação do súber na superfície da casca (rendilhamento). De acordo com Keren-Keiserman et al. (2004), o rendilhamento no fruto do meloeiro ocorre em resposta às rachaduras da superfície, as quais originam-se do rápido crescimento do fruto promovendo elevação da tensão de ruptura na casca, rompimento de células da epiderme, 
hipoderme e da cutícula. Essas rachaduras aprofundam-se, tornam-se mais largas e células da periderme iniciam a multiplicação, produzindo massa de células com paredes suberizadas que preenchem as rachaduras e se estendem acima da superfície do fruto. Nesse trabalho, plantas podadas a 16 folhas, ou seja, em condições de elevada competição fonte:dreno, obteve-se baixa qualidade dos frutos quanto ao rendilhamento, com valores inferiores a 75\%, evidenciando a importância de assimilados disponíveis para reticulação de casca. Higashi et al. (1999), observaram que frutos maiores apresentavam maior número de células na região do pericarpo, porém essas eram de menor tamanho, contribuindo para a maior formação do rendilhamento do fruto.

$\mathrm{O}$ aumento da EP constitui atributo de qualidade importante por se tratar da parte comestível do fruto do meloeiro (Coelho et al., 2003). Os resultados da EP obtidos neste trabalho foram maiores em frutos advindos de plantas com menor número de frutos e com maior número de folhas. Todavia, mesmo em plantas com dois frutos, a EP $(3,3 \mathrm{~cm})$ foi superior a encontrada por Purquerio \& Cecílio Filho (2005), em cultivo hidropônico do meloeiro híbrido Bônus $\mathrm{N}^{0} 2(\mathrm{EP}=3,1 \mathrm{~cm})$, também em planta conduzida com dois frutos.

Aumentos do CF e o DF ocorreram com a diminuição do número de frutos ou aumento do número de folhas por planta. De acordo com Valantin et al. (2006), o carregamento de frutos na planta afeta a taxa de crescimento e o tamanho final desses uma vez que, em frutos de melão, toda a expansão celular ocorre após a antese enquanto que a divisão celular continua em baixa taxa. Portanto, o número de células no final da antese é fator chave que contribui para com o tamanho final dos frutos, principalmente por causa de sua influência na habilidade dos frutos para atraírem assimilados. Em tomate, Bohner \& Bangerht (1988) observaram que a desfolha na planta ocasionou baixa produção de assimilados e redução no número de células nas regiões distal e proximal dos frutos 10 dias após a polinização, seguido pela redução do tamanho do fruto. Ainda, de acordo com

Tabela 2. Valores médios da reticulação da casca, espessura do mesocarpo, comprimento, diâmetro, diâmetro da cavidade, sólidos solúveis totais, acidez total titulável, açúcares solúveis totais, redutores e não redutores de frutos de meloeiro cultivado em ambiente protegido em função do número de frutos por planta (average values of netted peel, flesh thickness, lenght, diameter, diameter of cavity, soluble solids content, titratable acidity, total soluble sugars, reducers and no reducers sugars of melon fruit cultivated in greenhouse in relation to fruits number per plant). Viçosa, UFV, 2006.

\begin{tabular}{|c|c|c|c|c|}
\hline \multirow{2}{*}{ Característica } & \multicolumn{2}{|c|}{ Número de frutos } & \multicolumn{2}{|c|}{$\begin{array}{l}\text { Coeficiente de } \\
\text { variação }\end{array}$} \\
\hline & 1 & 2 & CV $(\%)^{1}$ & CV $(\%)^{2}$ \\
\hline Reticulação da casca & $4,5^{*} \mathrm{a}$ & $3,8 \mathrm{~b}$ & 1,07 & 3,87 \\
\hline Espessura da polpa (cm) & $3,8 \mathrm{a}$ & $3,3 \mathrm{~b}$ & 8,65 & 7,92 \\
\hline Comprimento do fruto $(\mathrm{cm})$ & $14,9 \mathrm{a}$ & $13,4 \mathrm{~b}$ & 2,51 & 5,48 \\
\hline Diâmetro do fruto $(\mathrm{cm})$ & $13,1 \mathrm{a}$ & $11,7 \mathrm{~b}$ & 4,03 & 3,49 \\
\hline Diâmetro da cavidade $(\mathrm{cm})$ & 5,6 a & $5,1 \mathrm{~b}$ & 3,34 & 5,51 \\
\hline Sólidos solúveis totais (\%) & $9,8 \mathrm{a}$ & $9,4 \mathrm{~b}$ & 2,43 & 5,30 \\
\hline Acidez total titulável (\% de ácido cítrico) & 0,088 a & $0,081 \mathrm{a}$ & 11,32 & 12,76 \\
\hline Açúcares solúveis totais $(\%)$ & $7,66 \mathrm{a}$ & $6,62 \mathrm{~b}$ & 5,80 & 7,66 \\
\hline Açúcares redutores $(\%)$ & $4,08 \mathrm{a}$ & $4,00 \mathrm{a}$ & 7,50 & 13,21 \\
\hline Açúcares não redutores (\%) & $3,58 a$ & $2,55 \mathrm{~b}$ & 11,80 & 20,54 \\
\hline
\end{tabular}

*Nas linhas, as médias seguidas pela mesma letra não diferem entre sí pelo teste Tukey ao nível de $5 \%$ de probabilidade. ${ }^{1}$ e ${ }^{2}$ Coeficientes de variação da parcela e subparcela. (In lines, means followed by same letter do not differ each other by Tukey test to $5 \% .{ }^{1}$ and ${ }^{2}$ plot split- plot variation coefficients).

Valantin et al. (2006), variações no tamanho final do fruto podem ser interpretadas como consequiência de dois processos: a força do dreno durante o período de divisão celular e a taxa de crescimento do fruto durante a expansão celular.

Maior DCF foi obtido de planta com um fruto e, independente do número de frutos, na poda a 20,8 folhas por planta. O aumento da cavidade não é desejável, pois quanto menor o espaço interno da cavidade melhor é o atributo de qualidade dos frutos do meloeiro rendilhado. Nesse trabalho, até certo ponto, o aumento do DCF esteve associado a condições que favoreceram o crescimento do fruto. Para Coelho et al . (2003), quase sempre o aumento do DCF reflete em fraca ligação da estrutura que contém as sementes e a polpa, podendo ocorrer o desprendimento das sementes e fermentação dos frutos no manejo pós-colheita, fatos não observados nesse trabalho.

Frutos advindos de plantas com apenas um fruto e com maior número de folhas apresentaram maiores valores de SST, AST e ANR. De acordo com Valantin et al. (2006), o teor de SST é um indicador direto da quantidade de sacarose nos tecidos do fruto do melão. Long et al. (2004), atribuem o maior teor de SST observados em frutos de plantas conduzidas com um fruto a maior disponibilidade e aporte de fotoassimilados para o fruto em razão da maior AF por fruto. Estes autores observaram valores de SST de 9,0 e de $7,8 \%$ em fruto do meloeiro quando as plantas foram conduzidas com um e dois frutos, respectivamente. Costa et al. (2004), também observaram que a competição por assimilados reduziu o teor de SST em fruto do meloeiro.

A manipulação da fonte pela redução de folhas, sobretudo, via eliminação de ramificações, tem sido examinada como método de controle de produção de flores; todavia seu efeito no teor de SST em frutos tem sido pouco relatado para o meloeiro. Porém, Long et al. (2004), verificaram que a desfolha em $50 \%$ da planta reduziu o SST em $1,0^{\circ}$ Brix, enquanto que, com $25 \%$ de desfolha, o efeito foi desprezível. Neste trabalho, a desfolha em 36\% (25 para 16 folhas) causou redução estimada de $1,0^{\circ}$ Brix no teor de SST da polpa do fruto.

Em melões em geral, a ATT varia de 0,05 a $0,35 \%$ de ácido cítrico (Mendlinger \& Pastenak, 1992). As 


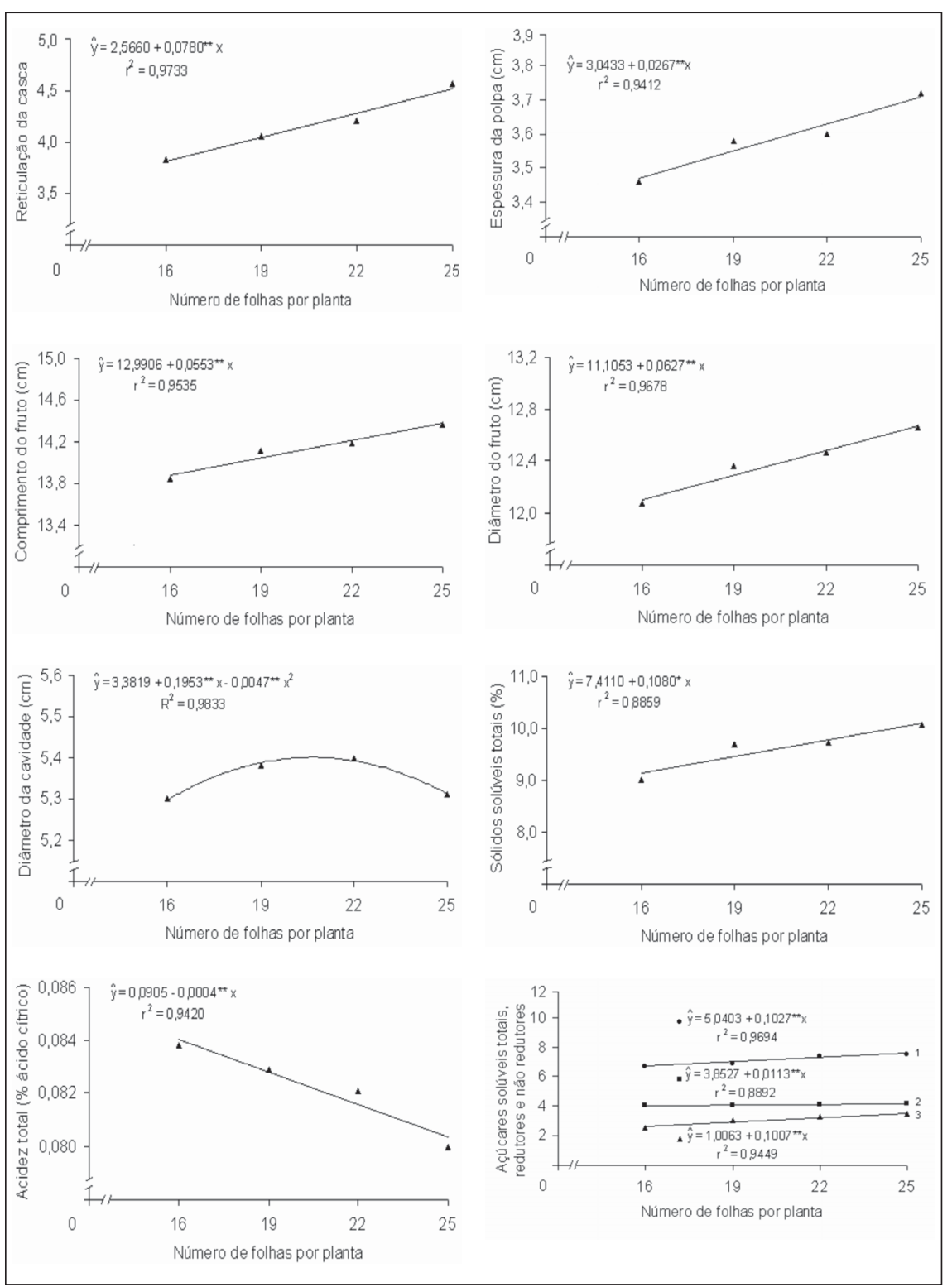

Figura 2. Estimativa da reticulação da casca, espessura do mesocarpo, comprimento e diâmetro, diâmetro da cavidade, teor de sólidos solúveis totais, acidez total, açúcares solúveis totais $\left({ }^{1}\right)$, açúcares redutores $\left({ }^{2}\right)$ e açúcares não redutores $\left({ }^{3}\right)$ de frutos de meloeiro cultivado em ambiente protegido em função do número de folhas por planta. ** e *: Significativo a 1 e $5 \%$ de probabilidade (estimate of netted peel, flesh thickness, length and diameter, diameter of cavity, soluble solids content, titratable acidity, total soluble sugars $\left({ }^{1}\right)$, reducers $\left({ }^{2}\right)$ and no reducers $\left({ }^{3}\right)$ sugars of melon fruit cultivated in greenhouse in relation to leaves number per plant. ** and * significant at 1 and $5 \%$ of probability). Viçosa, UFV, 2006.

médias de ATT obtidas neste trabalho situaram-se dentro do limite, e reduziram com o aumento do número de folhas por planta sem, contudo, alterar com o número de frutos por planta. Costa et al. (2004), também observaram redução na ATT no híbrido Bônus $\mathrm{N}^{0} 2$ em plantas com dois frutos, comparado a plantas com fixação livre de frutos.

O acúmulo de açúcares em frutos do meloeiro é influenciado pela atividade competitiva do dreno e pela disponibilidade da fonte. Durante o crescimento e desenvolvimento do fruto há necessidade de incremento na disponibilidade de carboidratos, seja pela redução do número de frutos ou pelo aumento da $\mathrm{AF}$ para que, próximo à colheita, após ter passado pelas fases de divisão e expansão celular, possa resultar em incremento nos açúcares armazenados no fruto (Long et al., 2004). A competição por assimilados reduz o teor de SST; por outro lado, SST está diretamente relacionado com o conteúdo de açúcares, razão pela qual esse se constitui em bom indicador do adoçamento (Valantin et al., 2006).

$\mathrm{O}$ fruto do meloeiro representa o principal dreno na planta e seu sabor depende dos fotoassimilados sintetizados e translocados da parte aérea durante o seu desenvolvimento (maturação), uma vez que esse não tem reserva de amido armazenada, à semelhança de frutos como banana, que poderiam incrementar o teor de açúcares pós-colheita via degradação do amido (Hubard \& Pharr, 1990). Os principais açúcares presentes em melão são a glicose e frutose (AR) e sacarose (ANR). Os AR contribuem com quase $100 \%$ do teor de açúcares solúveis totais (AST) na fase inicial de desenvolvimento dos frutos; todavia, na fase final da maturação (amadurecimento), a sacarose pode chegar até $50 \%$ dos AST, com proporção aproximada de $25 \%$ para glicose e $25 \%$ para frutose (Long et al., 2004). Neste trabalho, as participações de AR e ANR foram de 53,2 e $46,8 \%$ em plantas conduzidas com um fruto e de 60,0 e $40,0 \%$ em plantas com dois frutos, respectivamente. Observou-se, também, que a redução em $36 \%$ da $\mathrm{AF}$ ( 25 para 16 folhas), causou decréscimos de cerca 12,2, 1,8 e 25,7\% nas concentrações de AST, AR e ANR, respectivamente. Assim, frutos de plantas com menor número de folhas e maior número de frutos, proporcionalmente, tiveram menor teor de ANR, maior responsável pelo sabor. Portanto, é de fundamental importância, tanto para a produção quanto para a qualidade do fruto, suprimento adequando de fotoassimilados aos frutos durante todas as etapas da maturação.

\section{REFERÊNCIAS}

ANDRIOLO JL; FALCÃO LL. 2000. Efeito da poda de folhas sobre a acumulação de matéria seca e sua repartição para os frutos do tomateiro cultivado em ambiente protegido. Revista Brasileira de Agrometeorologia 8: 75-83.

BERTIN N; GARY C. TCHAMITCHIAN M; VAISSIÉRE BE. 1998. Influence of cultivar, fruit position and seed content in tomato fruit weight during a crop cycle and low and high competition for assimilates. Journal of Horticultural Science \& Biotechnology 73: 541-548. 
BERTIN N; GAUTIER H; ROCHE C. 2001. Number of cells in tomato fruits depending on fruit position and source-sink balance during plant development. Plant Growth Regulation 36: 105-112.

BOHNER J; BANGERTH F. 1988. Effects of fruit set sequence and defoliation on cell number, cell size and hormone levels of tomato fruit (Lycopersicon esculetum Mill.) within a truss. Plant Growth Regulation 7: 141-145.

COELHO EV; FONTES PCR; CARDOSO AA. 2003. Qualidade do fruto de melão rendilhado em função de doses de nitrogênio. Bragantia 62: 173-178.

COSTA, CC; CECÍlIO FILHO, AB; CAVARIANI, RL; BARBOSA, JC. 2004. Concentração de potássio na solução nutritiva e a qualidade e o número de frutos de melão por planta em hidroponia. Ciência Rural 34: 731-736.

FAGAN, EB; MEDEIROS, SLP; SIMON, J; LUZ, GL; BORCIONI, E; JASNIEWICZ, LR; CASAROLI, D; MAFRON, PA. 2006. Evolução e partição de massa seca do meloeiro em hidroponia. Acta Scientiarum. Agronomy 28: $165-172$.

HIGASHI K; HOSOYA K; EZURA H. 1999. Histological analysis of fruit development between two melon (Cucumis melo $\mathrm{L}$. reticulatus) genotypes setting a different size of fruit. Journal of Experimental Botany 50: 1593-1597.
HUBBARD NL; PHARR DM. 1990. Sucrose metabolism in ripening muskmelon fruit as affected by leaf area. Journal of the American Society for Horticultural Science 115: 798802.

KEREN-KEISERMAM A; TANAMI Z; SHOSEYO O; GINZBERG I. 2004. Differing rind characteristic of developing fruit of smooth and netted melons. Journal of Horticulural Science \& Biotechonoly 79: 107-113.

LONG RL; WALSH KB; ROGERS G; MIDMORE DJ. 2004. Source-sink manipulation to increase melon (Cucumis melo L.) fruit biomass and soluble sugar content. Australian Journal of Agricultural Research 55: 1241-1251.

MENDLINGER S; PASTENAK D. 1992. Effect of time, salination of flowering, yield and quality factors in melon, Cucumis melo L. Journal of the American Society for Horticultural Science 67: 529-534.

MILLER GL. 1959. Use of dinitrosalicylic acid reagent for determination reducing sugars. Analytical Chemistry 31: 426-428.

NOMURA ES; CARDOSO AII. 2000. Redução de área foliar e o rendimento do pepino japonês. Scientia Agrícola 57: 257-261.

PURQUERIO LFV; CECÍLIO FILHO AB. 2005. Concentração de nitrogênio na solução nutritiva e número de frutos sobre a qualidade de frutos de melão. Horticultura Brasileira 23: 831-836.
RAMIREZ DR; WEHNER TC; MILLER CH. 1988. Source limitation by defoliation and its effect on dry matter production and yield of cucumber. Hortscience 24: 704-706.

RIBEIRO AC; GUIMARÃES PTPG; ALVAREZ VH. 1999. Recomendação para o uso de corretivos e fertilizantes em Minas Gerais. UFV, Viçosa-MG, 359 p.

SEABRA JÚNIOR S; PANTANO SC; HIDALGO AF; RANGEL MG; CARDOSO AII. 2003. Avaliação do número e posição do fruto de melancia produzido em ambiente protegido. Horticultura Brasileira 21: 708-711.

TOPSEED AGRISTAR. 2007. Nova geração de híbridos. 16 de janeiro. Disponível em http:// www.agristar.com.br/.

VALANTIN M; GARY C; VAISSIERE BE; TCHAMITCHIAN M; BRUNELI B. 1998. Changing sink demand affects the area but not the specific activity of assimilates sources in cantaloupe. Annals of Botany 82: 711-719.

VALANTIN M; VAISSIERE BE; GARY C; ROBIN P. 2006. Source-sink balance affects reproductive development and fruit quality in cantaloupe melon. Journal of Horticultural Science \& Biotechnology 81: 105-117.

YEMN EW; WILLIS AJ. 1954. The estimation of carbohydrate in plant extracts by anthrote. The Biochemical Journal 57: 505-514. 